
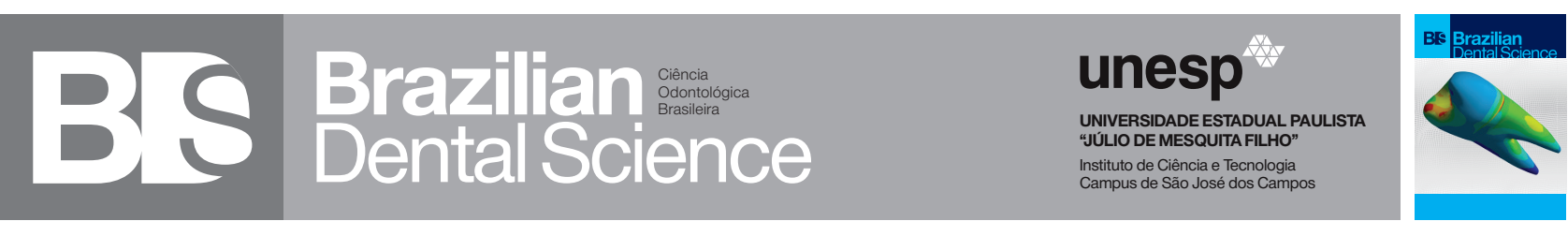

\title{
(i)
}

\section{Oral findings in West syndrome - A Case Report}

Achados bucais na síndrome de West- Relato de um caso

Sheetal BADNAWARE ${ }^{1}$, Shely DEDHIA ${ }^{1}$, Rajiv $S$ DESAI ${ }^{2}$, Adesh KAKADE ${ }^{1}$

1 - Department of Pediatric and Preventive Dentistry - Nair Hospital Dental College - Mumbai - India.

2 - Department of Oral and Maxillofacial Pathology - Nair Hospital Dental College - Mumbai - India

\begin{abstract}
West syndrome is a severe form of epilepsy syndrome which is characterized by a triad of infantile spasms, characteristic EEG findings (Hypsarrhythmia) and developmental delay. Minimal literature is available on dental findings of West syndrome. This case report presents an eight year old male child with cryptogenic form of West syndrome having a history of multiple clusters of infantile spasms. Orodental manifestations of west syndrome have been described and its dental management has been discussed in this report.
\end{abstract}

\section{KEYWORDS}

West syndrome; White spot lesion; Epilepsy; Infantile spasms.

\section{RESUMO}

A síndrome de West é uma forma severa da síndrome de epilepsia que é caracterizada pela tríade de espasmos infantil, achados EEG (hipsarritimia) e atraso no desenvolvimento. A literatura disponível é escassa a respeito dos achados dentais e manejo da síndrome de West. Este caso relata uma criança de 8 anos de idade, masculino com a forma criptogênica da síndrome de West com história de múltiplos episódios de espasmos infantis e achados dentais típicos. O tratamento odontológico do caso é discutido e mediadas preventivas e tratamento da síndrome de West é descrito.

\section{PALAVRAS-CHAVE}

Síndrome de West; Lesão de mancha branca; Epilepsia; Espasmos, infância.

\section{INTRODUCTION}

W est syndrome, a severe form of epilepsy syndrome, is a triad of infantile spasms (typical age when seizures start), hypsarrthymia and mental retardation [1]. The first detailed description of this condition was given by Dr. West in 1841 in his own four month old child as mentioned in the Lancet (1841) [2]. The condition is characterized by sudden flexion (bending forward) in a tonic (stiffening) fashion of the body, arms and legs. The incidence of West syndrome ranges from 2 to $3.5 / 10,000$ live births $[3,4]$. Onset is generally in the first year of life. The peak age of onset is between 3 to 7 months, though onset at 4 years of age has been reported [5]. Spasms usually cease by 5 years of age, but other seizure types are reported in as many as $60 \%$ of children with West syndrome even after cessation of spasms [5]. West syndrome occurs in all ethnic groups, and is more common in boys than girls (ratio of 60:40) [6]. Although various papers have been published on West Syndrome from a medical standpoint, there are very few articles available in the literature on orodental findings and treatment. This article documents the case of an 8 year old male child diagnosed with West Syndrome with more emphasis on the orodental findings and their dental treatment. 


\section{CASE REPORT}

An eight year old male child reported to the Department of Pediatric and Preventive Dentistry with the chief complaint of pain in the lower right back teeth region since 10 days. Detailed medical history of the child was taken. Patient was a known case of cryptogenic form of West syndrome and was diagnosed at the age of one and a half years. The child had normal motor developmental milestones till one year of age, then he had recurrent myogenic epilepsy and EEG findings showed hypsarrthymia and infantile spasms which helped in his diagnosis. The last episode of convulsion was at the age of seven years threemonths. Patient had poor communication skills, delayed social skills and an aggressive behavior. Patient has been taking oral antiepileptic medication syp. Levetiracetam (Keppra) $2.5 \mathrm{ml} \mathrm{BD}$ since last 7 years. The patient is the third child from a non-consanguineous marriage. Other two siblings were healthy and did not have any medical history. On physical examination, the neuromuscular delay was the most evident characteristic and there was atrophy of the upper and lower limbs (Figure 1 and 2). The child did not cooperate for thorough intraoral examination. Initially, symptomatic pain management was done with Syp.Paracetamol $(125 \mathrm{mg} / 5 \mathrm{ml})$ and further dental treatment was planned under general anesthesia. The necessary blood and radiographic investigations were done and pediatric and neuromedicine opinions were taken. Written consent for dental treatment under general anesthesia was obtained from the parents and after evaluating all investigations, the patient was scheduled for dental treatment under general anesthesia.

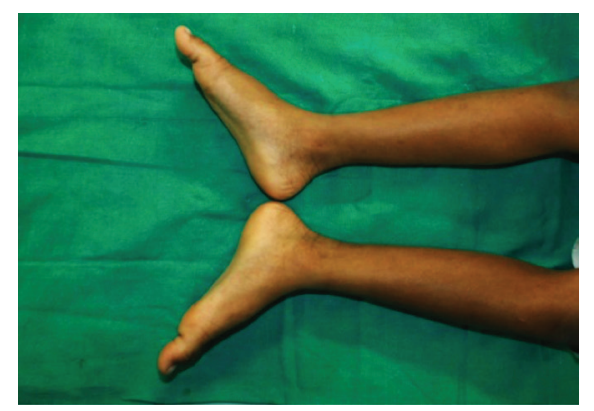

Figure 1 - Atrophy of lower limbs

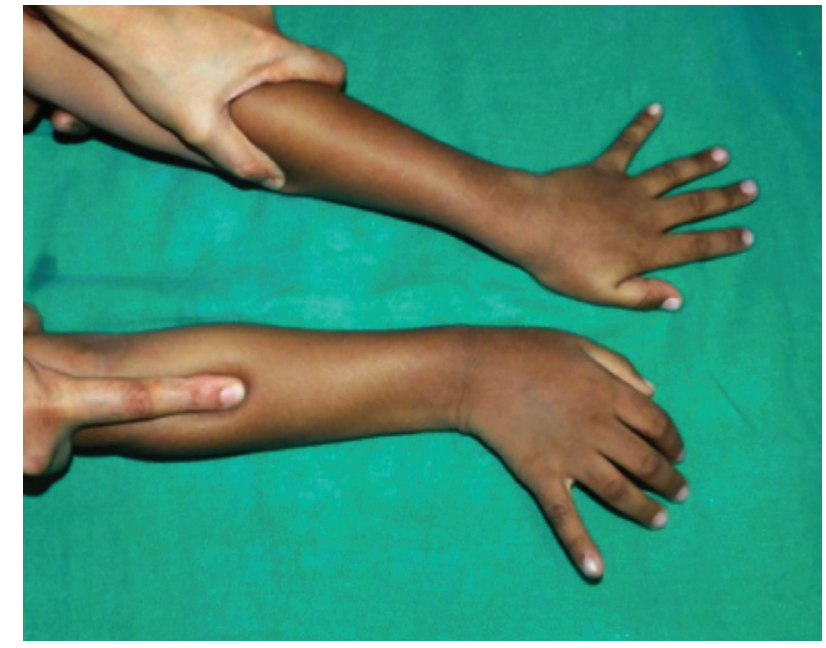

Figure 2 - Atrophy of upper limbs

The intra oral examination was done and intra oral periapical radiographs (IOPA) [Figure 7] were taken under general anesthesia. The intra oral examination showed that the patient had mixed dentition. 64,65,73,74,75,84,85 had carious lesions, out of which 74,75,84 and 85 had multisurface carious lesions [Figure 3 and 4]. On radiographic assessment, these teeth showed root resorption. Generalized attrition of all primary teeth was seen with hypoplastic white spots on the labial surfaces of 31 and 41 [Figure 5]. Angle's class I molar relationship was noted on both sides with deep arched palate and anterior open bite [Figure 6].

Glass ionomer cement restoration in 64,65,73 and extraction of 74,75,84 and 85 were done. Oral prophylaxis and topical fluoride varnish application was done [Figure 8 and 9]. The child recovered and accepted general anesthesia well.

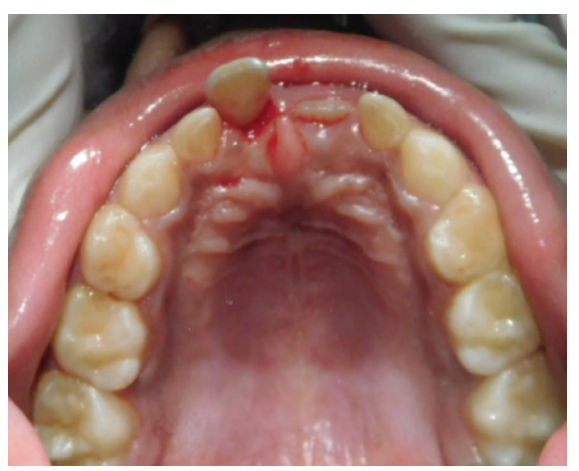

Figure 3 - Preoperative view of maxillary arch 


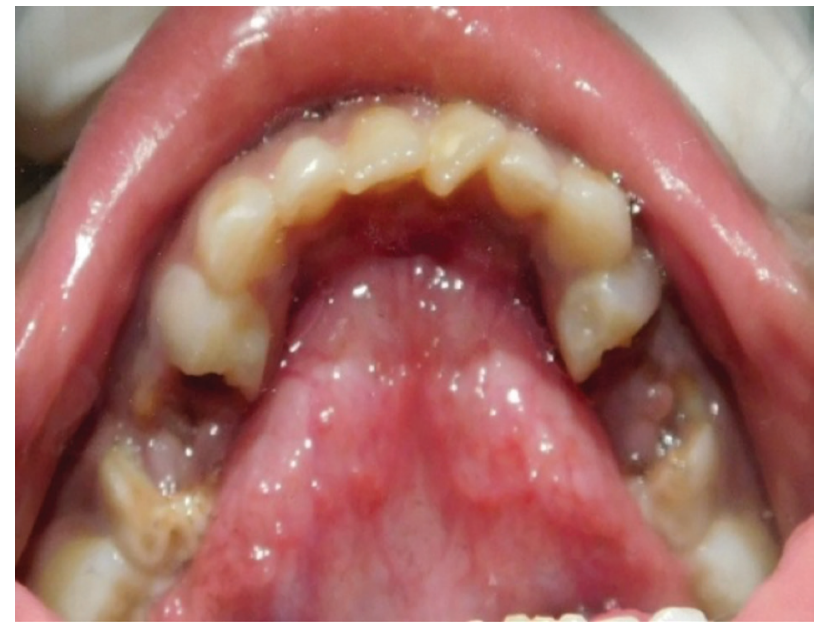

Figure 4 - Preoperative view of mandibular arch

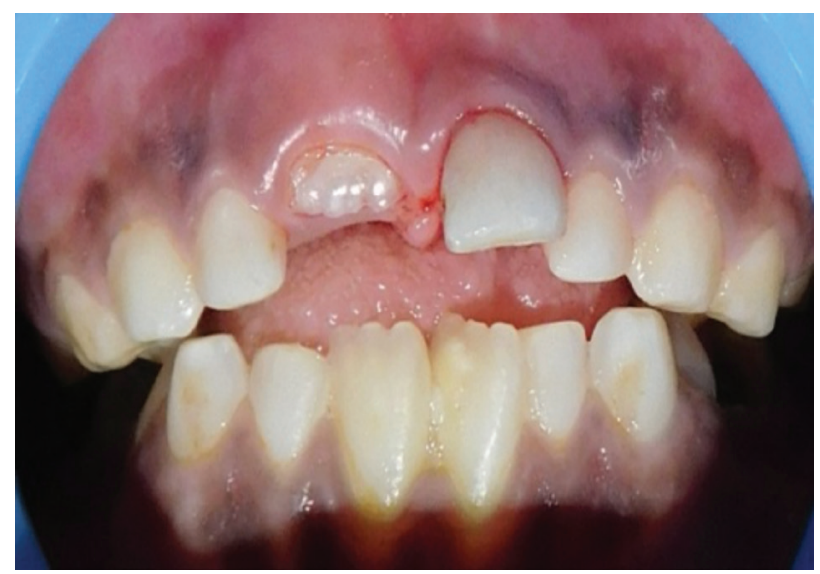

Figure 5 - White spot lesions on 31 and 41

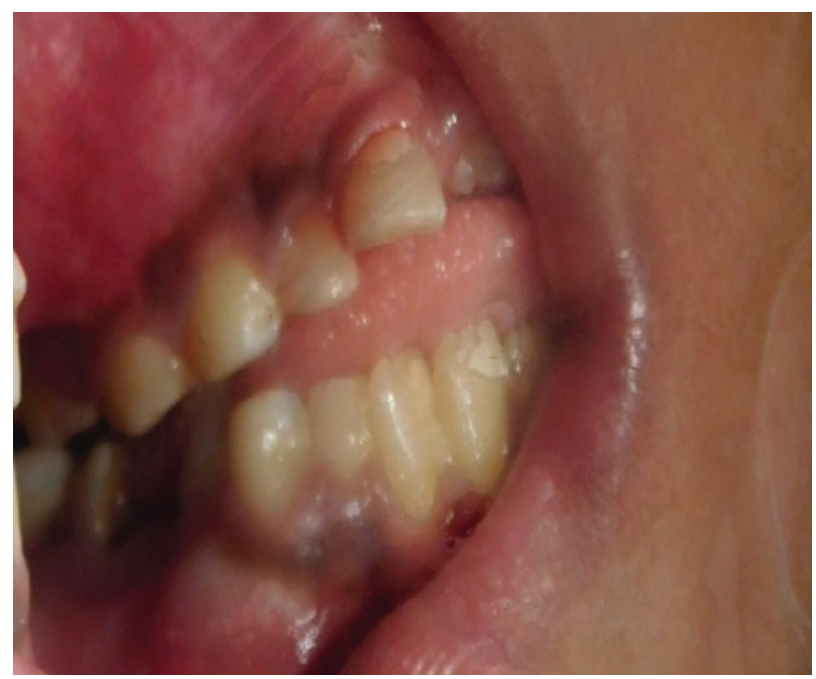

Figure 6 - Intraoral view showing angle class I molar relationship

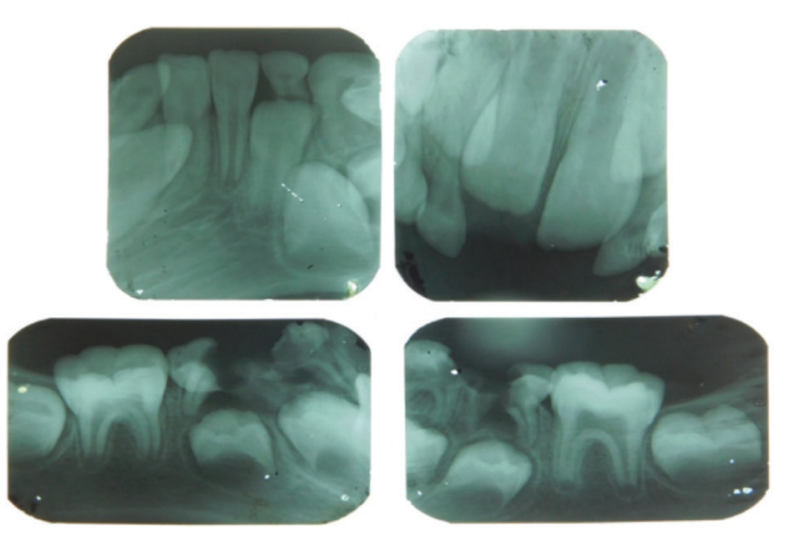

Figure 7 - IOPA - Upper row- mandibular anterior and maxillary anterior region and Lower row- mandibular left and right posterior region

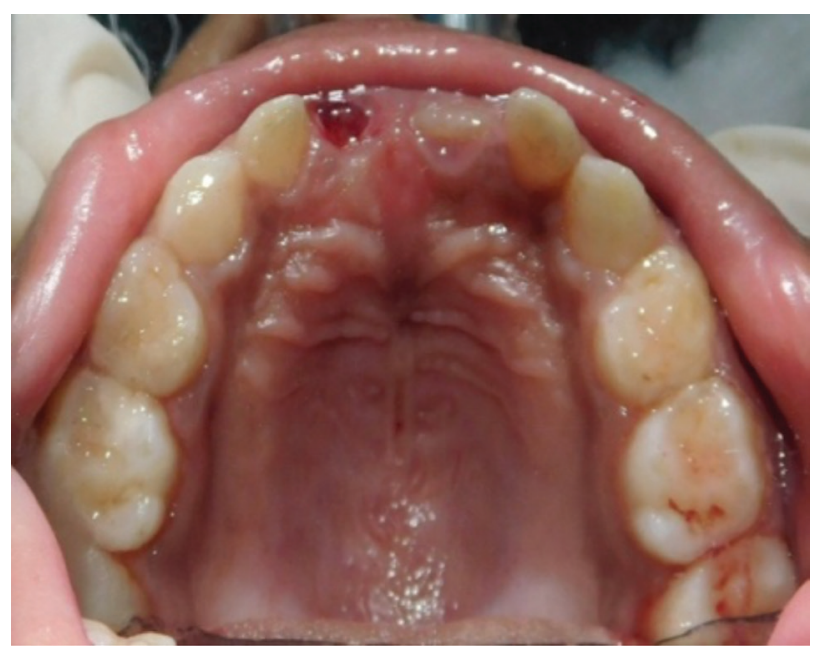

Figure 8 - Postoperative view of Maxillary arch

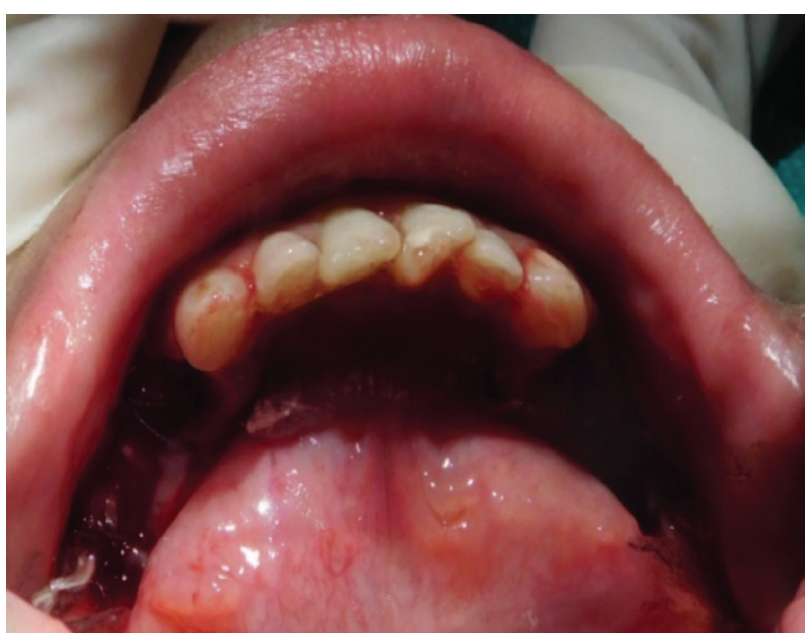

Figure 9 - Postoperative view of Mandibular arch 


\section{DISCUSSION}

According to etiologic classification, West syndrome is divided into two types i.e. Cryptogenic and Symptomatic [7]. The cryptogenic form of West Syndrome is mostly idiopathic, with an unknown cause; whereas the symptomatic variety can be attributed to prenatal, natal and post-natal causes [8].

Sparse information is available in the dental literature which emphasizes on the orodental findings and dental management of West syndrome patients. Parents of children with special healthcare needs find it difficult to maintain good oral hygiene owing to the child's low IQ level, limited communication skills and lack of manual dexterity [9]. Dentists need to place more emphasis on preventive dental care of such patients to avoid future dental problems. The importance of family commitment to daily oral hygiene and avoidance of a cariogenic diet should be encouraged.

Case reports on West syndrome documented by Regis[10], Neta[11] and Khatri et al. [12] showed similar intra oral findings i.e. multiple white spot lesions on labial surfaces, generalized tooth wear, altered chronology of teeth and gingival inflammation. Regis [10] found a deep arched palate, delayed eruption of permanent lower incisors and permanent first molars. Gingival enlargement is likely due to poor oral hygiene and white spot lesions are due to high sucrose diet and sugar containing medications. Neta[11] reported other oral findings like anterior open bite with tongue interposition in between arches, altered chronology, fissured tongue and low caries experience.

As there are many other conditions with similar orofacial findings like Rett's syndrome, cerebral palsy, Angelman's syndrome, Lennox gastaut syndrome etc., a dental surgeon should be aware regarding the clinical and oral presentation of West syndrome. Awareness about the importance of prompt diagnosis and timely treatment of patients with special health care needs should improve for better long-term outcomes. To provide treatment for patients with special health care needs, a dentist must evaluate each patient thoroughly in terms of personal characteristics, symptoms and behavior. The dentist should never make assumptions about the child's degree of impairments without taking thorough medical and dental history. Parent or guardians should be interviewed for detailed history. Parental education and training is required to improve the oral hygiene of special children. This case report is of practical significance to the dentist in treating a patient with West syndrome.

\section{CONCLUSION}

As the oral health is a vital part of overall well being and general health, dental professionals should be included in the multidisciplinary health care team. Dentists should become familiar with the clinical features of West Syndrome in order to provide good dental care to patients.

Conflict of interest: No conflict of interest

Source of funding: None

\section{REFERENCES}

1. Taghdiri MM, Nemati H. Infantile spasm: a review article. Iran J Child Neurol. 2014 Summer;8(3):1-5.

2. Wong V. West syndrome-the University of Hong Kong experience (1970-2000). Brain Dev. 2001 Nov;23(7):609-15.

3. Sidenvall R, Eeg Olofsson 0. Epidemiology of infantile spasms in Sweden. Epilepsia. 1995 Jun;36(6):572-4.

4. Cowan LD, Bodensteiner JB, Leviton A, Doherty L. Prevalence of the epilepsies in children and adolescents. Epilepsia. 1989 JanFeb;30(1):94-106.

5. Wheless JW, Gibson PA, Rosbeck KL, Hardin M, O'Dell C, Whittemore V, et al. Infantile spasms (West syndrome): update and resources for pediatricians and providers to share with parents. BMC Pediatr. 2012 Jul 25;12:108. doi: 10.1186/1471-2431-12-108.

6. Riikonen R.Epidemiological data of West syndrome in Finland. Brain Dev. 2001 Nov;23(7):539-41.

7. Riikonen RS. Favorable prognostic factors with infantile spasms. Eur J Paediatr Neurol. 2010 Jan;14(1):13-8. doi: 10.1016/j. ejpn.2009.03.004. Epub 2009 Apr 11.

8. Oliveira JS, Prado Júnior RR, de Sousa Lima KR, de Oliveira Amaral $\mathrm{H}$, Moita Neto JM, Mendes RF. Intellectual disability and impact on oral health: a paired study. Spec Care Dentist. 2013 NovDec;33(6):262-8. doi: 10.1111/scd.12015. Epub 2013 Mar 11. 
9. Matsuo A, Matsuzaka T, Tsuru A, Moriuchi H, Nakashita Y, Tanaka S, Baba C, Tomimasu K. Epidemiological and clinical studies of West syndrome in Nagasaki Prefecture, Japan. Brain Dev. 2001 Nov;23(7):575-9.

10. Regis RR, Rocha CT, Torres CP, Queiroz IF, De Queiroz AM. Oral findings and dental treatment in a child with West syndrome. Spec Care Dentist. 2009 Nov-Dec;29(6):259-63. doi: 10.1111/j.17544505.2009.00106.x.

11. Dantas-Neta NB, Carvalho e Souza CH, Mendes Alencar SM, Prado Júnior RR, Mendes RF. Dental findings in children with West syndrome. Spec Care Dentist. 2014 Nov-Dec;34(6):291-4. doi: 10.1111/scd.12068. Epub 2014 Feb 20.
12. Khatri A, Kalra N, Tyagi R, Baweja M, Khandelwal D. Denta findings in patients with West syndrome: A report of two cases. J Indian Soc Pedod Prev Dent. 2014 Apr-Jun;32(2):168-71. doi: 10.4103/0970-4388.130988.

13. Tan H, Gürbüz T, Dağsuyu IM. Gingival enlargement in children treated with antiepileptics. J Child Neurol. 2004 Dec;19(12):958-63.

14. Lafzi A, Farahani RM, Shoja MA. Phenobarbital-induced gingival hyperplasia. J Contemp Dent Pract. 2007 Sep 1;8(6):50-6.

\section{Dr. Adesh Kakade \\ (Corresponding address)}

Professor and Head

Department of Pediatric and Preventive Dentistry

Nair Hospital Dental College, Mumbai - 400008

Dr. A.L.Nair Road, Mumbai Central. Mumbai - 400008

Maharashtra

Date submitted: 2017 Feb 03

E-mail - adeshkakade@gmail.com

Accept submission: 2017 May 15 